\title{
Onça, veado, Maria: literatura infantil e performance em uma pesquisa sobre diversidade cultural em sala de aula
}

\section{Jaguar, deer, Maria: children's literature and performance in a research on cultural diversity in the classroom}

\author{
Luciana Hartmann*
}

\begin{abstract}
RESUMO
O artigo analisa os resultados do projeto "Pequenas Antropologias: uma proposta colaborativa de formação de educadores para o trabalho com a diversidade cultural no Ensino Fundamental", desenvolvido entre 2014 e 2016 em escolas públicas do Distrito Federal, para refletir sobre a operatividade do uso de pedagogias performativas na vivência e problematização da diversidade em sala de aula.

Palavras-chave: Performance. Educação. Diversidade. Antropologia. Literatura infantil.
\end{abstract}

\begin{abstract}
The article analyzes the results of the project "Little Anthropologies: a collaborative proposal for training teachers to work with cultural diversity in Elementary School", developed between 2014 and 2016 in Distrito Federal public schools. The purpose is to reflect on the use of performative pedagogies in the experience of diversity in the classroom.
\end{abstract}

Keywords: Performance. Education. Diversity. Anthropology. Children's literature.

* Universidade de Brasília. Complexo das Artes. Brasília, Distrito Federal, Brasil. E-mail: luhartm@yahoo.com.br. http://orcid.org/0000-0003-1203-5027 
A onça não estava entendendo nada. Nem Joaci.

Será que, para a onça, o sangue era mesmo cauim? Para Joaci, o cauim da onça era sangue. Será que, para a onça, o cocô era frutinha? Para Joaci, a frutinha era cocô. E será que a cobra era mesmo milho cozido para a onça? Se fosse assim, eles viam as coisas de maneiras diferentes.

"Onde a onça bebe água", de Verônica Stigger, a partir da obra de Eduardo Viveiros de Castro

Somos diferentes, vemos as coisas de maneiras diferentes, nossos corpos e nossas sexualidades são diferentes, mas... nossas histórias por vezes se parecem. Proporcionar a produção e a escuta dessas histórias, problematizando o lugar da diversidade em sala de aula, foi o objetivo do projeto "Pequenas Antropologias: uma proposta colaborativa de formação de educadores para o trabalho com a diversidade cultural no Ensino Fundamental”, realizado entre 2014 e 2016 em duas escolas públicas do Distrito Federal ${ }^{1}$. A partir da apresentação das diferentes etapas do projeto, este artigo pretende defender que, por meio de "pedagogias performativas" (PINEAU, 2005; ICLE; BONATTO, 2017), podem-se vivenciar exercícios concretos, corporificados, compartilhados, de reflexão, compreensão e tolerância à diversidade.

Com formação marcadamente interdisciplinar, em Teatro e Antropologia, minha trajetória tem sido marcada pela estreita relação com os Estudos da Performance que, como já demonstrei em outros momentos (HARTMANN, 2014; 2015), vêm se mostrando uma excelente ponte teórico-metodológica entre essas duas áreas. No intuito de não me repetir e de reforçar a parceria que vem unindo vários colegas brasileiros na intersecção entre Performance e Educação, vou me servir aqui das excelentes definições oferecidas por Gilberto Icle e Mônica Bonatto, em artigo recentemente lançado nos Cadernos Cedes, para situar o que, como eles, considero a potência da noção de performance na análise das relações escolares contemporâneas:

[...] circunscreve-se não apenas no diagnóstico (pensar a escola como performance), mas também na proposição (pedagogias performativas),

1 Projeto financiado com recursos do edital Universal do Conselho Nacional de Desenvolvimento Científico e Tecnológico (CNPq) 2014, foi coordenado por mim e pelo antropólogo Guilherme José da Silva e Sá (Universidade de Brasília) e contou com a colaboração das pesquisadoras da área da Pedagogia do Teatro, Marina Marcondes Machado (Universidade Federal de Minas Gerais) e Taís Ferreira (Universidade Federal de Pelotas), às quais agradecemos pelas excelentes contribuições. 
pois a qualidade da performance (o performativo) é a capacidade que ela tem de nos mostrar a transformação como fator essencial da ação humana: na performance fazemos alguma coisa que nos permite refazer-nos a nós mesmos. (ICLE; BONATTO, 2017, p. 9).

Acredito que ideia de que a performance nos permite refazer-nos a nós mesmos é especialmente relevante para pensar/sentir/fazer a diversidade em sala de aula: como cada um de nós (professores \& alunos) está disposto a olhar o "outro" e a mudar seu olhar sobre esse outro ${ }^{2}$. Os deslocamentos, reposicionamentos das relações e a radicalização dos contatos (físicos, emocionais) provocados pela performance possibilitam experiências não usuais no ambiente escolar: a performance é inerentemente interativa e fundamentalmente arriscada, diz o antropólogo britânico Edward Schieffelin (1997, p. 198). Não se trata mais de "ensinar", mas de interrogar, descobrir, desconfiar, experimentar, vivenciar, compartilhar pedagogias que se estão sempre "em processo" e que só são possíveis na relação, em contextos específicos, com sujeitos específicos. Como reforça Victor Turner, a performance tem um sentido processual, de "levar à completude" ou "realizar" (2015, p. 130).

Antes de tratar diretamente da execução do projeto, acredito que seja importante situar meu "lugar de fala". Tenho formação em Teatro e em Antropologia. Atuando há mais de dez anos como Avaliadora de Cursos de Graduação do INEP, pude constatar que, embora um dos temas transversais definidos nos Parâmetros Curriculares Nacionais (PCN, 1997) seja a Pluralidade Cultural, há ainda pouco investimento neste tema nos Projetos Pedagógicos dos Cursos de Licenciatura em Teatro e Artes Cênicas no Brasil. Nas Licenciaturas em Ciências Sociais e, mais especificamente, de Antropologia, o quadro não é muito diferente. Percebe-se que a Lei n ${ }^{\circ} 11.645$, de 10/03/2008 e a Resolução CNE/CP n ${ }^{\circ} 01$, de 17 de junho de 2004, que dizem respeito às Diretrizes Curriculares Nacionais para Educação das Relações Étnico-raciais e para o Ensino de História e Cultura Afro-Brasileira e Indígena, encontram-se em fase inicial de implementação em grande parte desses cursos, preparando ainda de forma insuficiente os futuros professores da área para lidarem com a diversidade cultural dos alunos e com consequentes os conflitos e tensões com os quais irão se deparar quando do exercício da profissão. No contexto atual, de grave crise política em nosso país, que põe em risco conquistas ainda não inteiramente implementadas, acredito

2 O debate crítico sobre a "invenção do outro", promovida pelo movimento Modernidad/ Colonialidad (CASTRO GOMEZ, 2005) poderia gerar um desdobramento fértil para a discussão aqui proposta, porém infelizmente não cabe nos limites deste artigo. 
que as pedagogias performativas, que promovem processos de coautoria entre professores e alunos, valorizando as vozes, posicionamentos, ações das crianças e investindo no protagonismo destas, possam contribuir para a inserção efetiva do debate sobre pluralidade e diversidade cultural nas escolas públicas brasileiras.

Adotando uma perspectiva transdisciplinar, no intuito de preservar direitos previstos nos mencionados PCNs, que preveem dentre os objetivos gerais do Ensino Fundamental "conhecer e valorizar a pluralidade do patrimônio sociocultural brasileiro, bem como aspectos socioculturais de outros povos e nações, posicionando-se contra qualquer discriminação baseada em diferenças culturais, de classe social, de crenças, de sexo, de etnia ou outras características individuais e sociais" (PCN, 1997: 6), propomos o diálogo com a Antropologia, enquanto campo de saber que se dedica a perceber e refletir sobre estas questões e que pode, assim, contribuir de forma direta no trabalho desenvolvido em sala de aula.

O cotidiano de mais de 15 anos de convívio em sala de aula com estudantes que ingressam nas universidades públicas brasileiras tem fornecido indicativos da impermeabilidade de certo pensamento voltado para a vivência intercultural. É preciso que os professores das licenciaturas em geral lancem mão de um esforço redobrado para promover o debate crítico sobre o conteúdo programático de suas disciplinas e desconstruir pré-noções arraigadas em função de uma educação fundamental de cunho positivista e, muitas vezes, dogmática. Essas ações são necessárias tendo em vista que estes alunos, futuros professores, vão se deparar com realidades sociais e culturais múltiplas no exercício da profissão. Elyse Pineau também constata esta demanda: "Como professores têm crescentemente se defrontado com salas de aula culturalmente diversas, eu acredito que nós precisamos estar preparados para um espectro mais abrangente do comportamento dos estudantes." (PINEAU, 2013, p. 45) ${ }^{3}$ Por mais que se reconheça tal diversidade, esta se confronta com os limites de uma natureza homogeneizante inscrita na educação e na base da instituição mais representativa desse universo: a escola, do nível fundamental ao universitário (PENA-RUIZ, 2005).

Para que floresça uma postura de enfrentamento às naturalizações decorrentes de um ambiente educacional propagador do senso comum é necessário que os próprios professores passem a questionar a suposta "neutralidade cultural" da escola "demarcando uma postura crítica com relação aos discursos produzidos em torno desta suposta neutralidade, subsidiando o educador em formação para

3 Pineau, conforme nos informa Icle (2010), é uma das pioneiras na interseção entre Performance e Educação. Importante ressaltar ainda que a autora, norte-americana, assume ter sido francamente inspirada na educação libertadora de Paulo Freire para o desenvolvimento de sua pedagogia performativa crítica. 
a desconstrução de tal concepção, o que só é possível quando compreendemos a cultura numa perspectiva plural e polifônica." (OLIVEIRA, 2012, p. 128)

Consideramos que a melhor forma de enfrentar este problema fundacional seria investir na composição de massa crítica aprimorando a formação de nossos licenciandos valendo-nos de estudos sobre diversidade cultural aliados a vivências práticas na escola.

"Pequenas Antropologias" teve início em 2014, quando realizava meu pós-doutoramento pesquisando, em escolas públicas francesas, como crianças imigrantes contavam suas histórias ${ }^{4}$. O contato com a extrema pluralidade étnica, religiosa, social, linguística e de classe, encontrada nas chamadas CLIN, Classes de Iniciação para crianças não-francófonas, e com as políticas educacionais francesas para a integração de crianças estrangeiras, inspiraram a mim e ao professor Guilherme Sá a desenvolvermos uma pesquisa que fornecesse subsídios teóricos e metodológicos aos licenciandos de Artes Cênicas e de Ciências Sociais para o trabalho com a diversidade cultural em sala de aula. Para tanto, contamos com a colaboração de três alunas de iniciação científica (IC), Amanda Sucupira (Antropologia), Luênia Guedes e Isadora Rodrigues (Artes Cênicas). A pesquisa teve 5 etapas, que serão detalhadas abaixo: 1. survey; 2. leitura e análise das obras de literatura infantil; 3. revisão da literatura sobre infância e mediação de literatura; 4. Pesquisa de campo / prática na escola; 5. Análise dos dados e redação dos relatórios finais.

\section{Survey - o que os antropólogos brasileiros leem para suas crianças}

A pesquisa nas escolas francesas foi pautada pela leitura e contação de histórias e pela escuta das crianças, que produziam e performatizavam suas próprias narrativas. Compreendendo a importância da literatura na formação do imaginário e no desenvolvimento dos valores éticos e morais dos sujeitos, iniciamos o projeto com uma pesquisa pela internet, realizada através do software Survey Monkey, através da qual perguntávamos (1) o que os antropólogos brasileiros liam para as crianças com as quais conviviam, (2) com que frequência liam e (3) solicitávamos a indicação de dois títulos, em língua portuguesa, que fossem

4 O Projeto "Pequenos narradores: o que contam as crianças de diferentes tradições narrativas?" foi desenvolvido entre fevereiro de 2014 e fevereiro de 2015, sob supervisão da profa. Dra. Idelette Muzart Fonseca dos Santos, da Université Paris Ouest Nanterre - La Défense, e contemplado com Bolsa de Estágio Sênior da CAPES. 
importantes na formação das crianças para o convívio multicultural, pluriétnico, multinatural, multiestético, de diversidade de gênero, entre outros. O link para a pesquisa foi divulgado por meio das redes sociais e ficou disponível por um mês. Finalizado este período, pudemos contar com 138 respondentes, que não eram identificados. A primeira pergunta foi respondida por todos, a segunda por 129 respondentes e a terceira gerou a indicação de 72 títulos de livros infantis, sendo que alguns desses foram mencionados por mais de um respondente.

Em relação às respostas à questão 1: Que tipo(s) de livro(s) você costuma(va) ler para / com suas crianças? Percebe-se que a maioria $(77,54 \%)$ indicou ler Literatura Brasileira, que foi seguida por Contos tradicionais, mitos e lendas $(73,91 \%)$. Segue o quadro demonstrativo completo abaixo:

\section{QUADRO 1 - GÊNEROS LITERÁRIOS \\ Pequenas antropologias \\ Q1 Que tipo(s) de livro(s) você costuma(va) ler para / com suas crianças?}

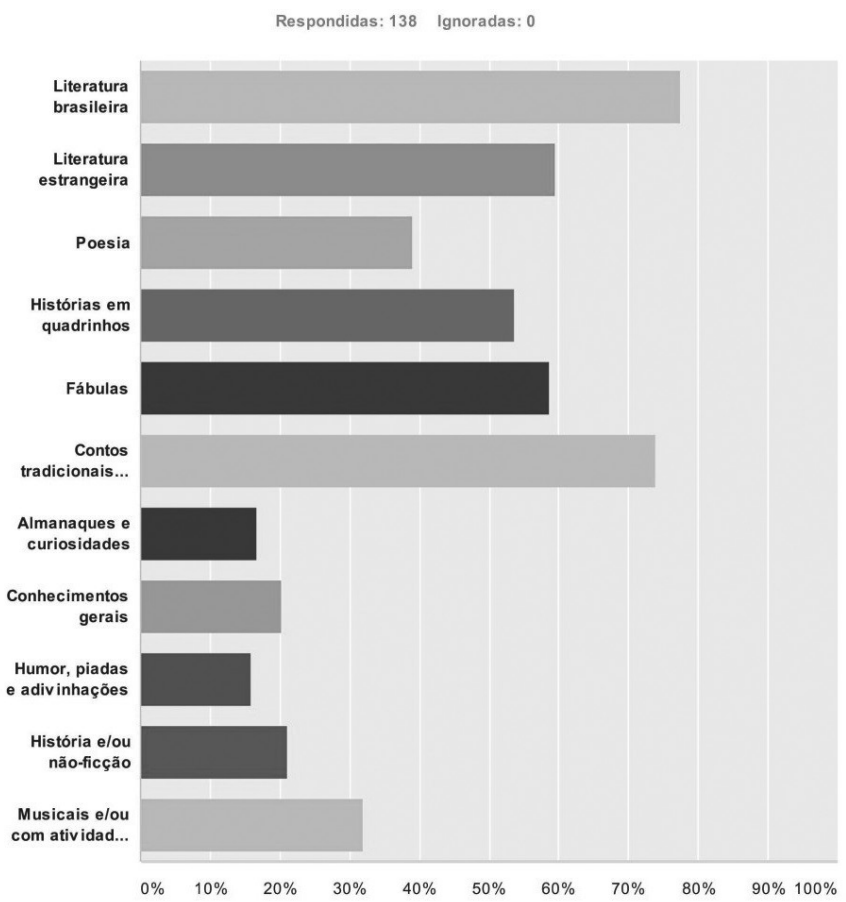

FONTE: Survey Monkey 
Já a pergunta 02 "Com que frequência você realiza (ou realizou) esta atividade de leitura conjunta?" teve respostas bastante equilibradas, com 30,23\% informando lerem de três a cinco vezes por semana, 26,36\% informando que liam todos os dias e o mesmo percentual, $26,36 \%$, que lia uma ou duas vezes por semana.

\section{QUADRO 2 - FREQUÊNCIA DE LEITURA}

\section{Pequenas antropologias \\ Q2 Com que frequência você realiza (ou realizou) esta atividade de leitura conjunta?}

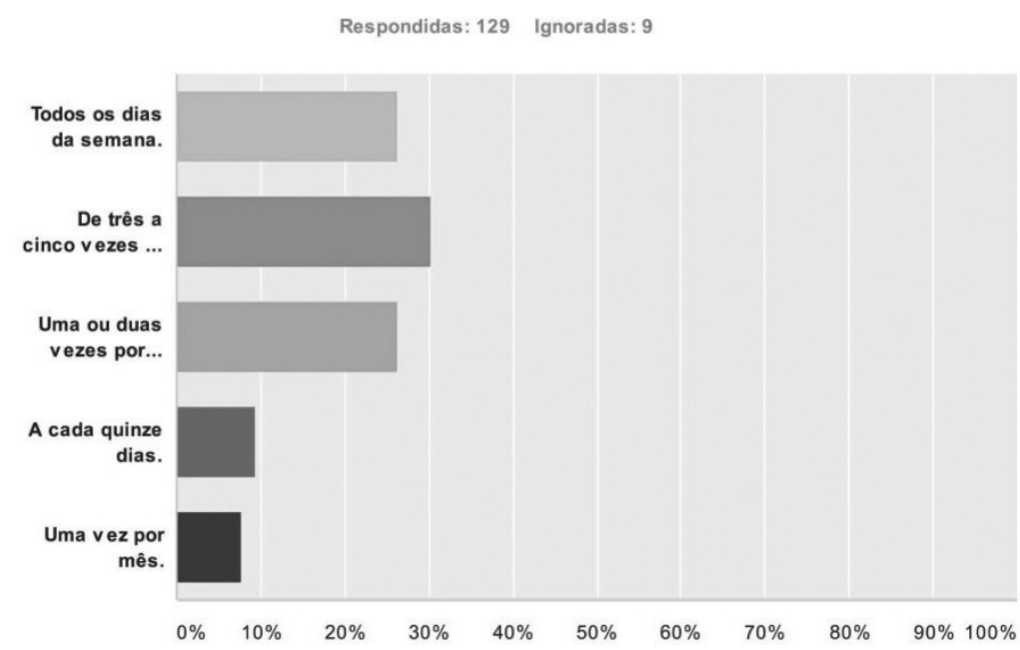

FONTE: Survey Monkey

Na impossibilidade de listar todos os livros indicados em resposta à terceira questão, faremos uma síntese dos principais títulos, autores, temas e gêneros sugeridos. Um primeiro aspecto que pode ser observado foi a menção a autores brasileiros bastante reconhecidos, como Ruth Rocha, com Viva a diferença, Pedrinho Pintor e Nicolau tinha uma ideia; Ana Maria Machado, com Menina Bonita do Laço de Fita, Ricardo Azevedo, com Contos de Bichos do Mato e No meio da noite escura tem um pé de maravilha, Ângela Lago, com Sete Histórias para sacudir o esqueleto, Ziraldo, com O Menino Maluquinho e Flicts e Chico Buarque, com Chapeuzinho Amarelo. Outro aspecto relevante são os livros com 
claros recortes étnicos ou de gênero, como Cabelo de Lelê, de Valéria Belém, Falando banto, de Eneida D. Gaspar, Ogum, o rei de muitas faces e outras histórias dos orixás, de Lidia Chaib e Elizabeth Rodrigues, O Onça, de Daniel Munduruku, Ticuna - O livro das árvores, organizado por Jussara Gomes Gruber, Meus Dois Pais, de Walcyr Carrasco, O menino Nito... então, homem chora ou não?, de Sonia Rosa, Kiriku e a feiticeira, de Michel Ocelot ou Minhas imagens do Japão, de Etsuko Watanabe. Um terceiro aspecto que merece destaque são os livros que exploram a linguagem poética e/ou a linguagem visual, como $A$ árvore generosa, de Shel Silverstein, Contos para Crianças Impossíveis, de Jacques Prévert, A mulher que matou os peixes e Quase de verdade, de Clarice Lispector, Lili inventa o mundo, de Mário Quintana, O menino que queria virar vento, de Pedro Kalil Auad, Onda, de Suzy Lee, O pote vazio, de Demi, Os livros voadores de Modesto Máximo, de William Joyce, Lampião e Lancelote, de Fernando Vilela ou Era uma vez... em cordel, de Arievaldo Viana. Foram indicados ainda diversos contos de fadas e clássicos da literatura ocidental, como João e o Pé de Feijão, Alice no País das Maravilhas e O Pequeno Príncipe.

\section{Leitura e Análise - o que contam os livros infantis}

A despeito da alta qualidade, tanto gráfica quanto de conteúdo, da literatura infantil brasileira, que aborda direta ou indiretamente a diversidade cultural, e do fato de que o Ministério da Educação tem investido maciçamente na aquisição desta bibliografia, verifica-se que muitos livros não têm chegado ao seu destino (as bibliotecas escolares) e, portanto, também não atingem seus leitores, as crianças (PAIVA, 2012). Sem os livros, a riqueza de seus conteúdos dificilmente será acessada pelos estudantes. Por este motivo, nesta etapa do projeto foram adquiridos grande parte dos livros mencionados no survey, além de outros, não mencionados, mas com temáticas ou abordagens semelhantes, como "Onde a onça bebe água”, mencionado na epígrafe deste artigo, de forma a proporcionar, ainda que de forma bastante modesta, o acesso das crianças das escolas públicas a algumas obras que tratem desses temas específicos.

As pesquisadoras de IC, em conjunto com os professores coordenadores do projeto, dividiram-se para realizar a leitura das obras de literatura infantil adquiridas. Em reuniões semanais, os livros lidos eram apresentados e discutidos. No final dessa etapa, as licenciandas escolheram alguns livros para utilizarem em seus planos de aula, diretamente com as crianças. 


\section{Revisão da literatura sobre infância, diversidade e mediação de literatura}

Foi solicitado a cada jovem pesquisadora que selecionasse, no mínimo, quatro textos relacionados aos estudos da infância, diversidade e de mediação de literatura infantil para realizar fichamentos individuais e posteriormente debatê-los nas reuniões com o grupo. Foram lidos trabalhos de Clarice Cohn (2005) sobre antropologia da criança, de Rosa Hessel Silveira (2013), sobre literatura infantil e diversidade e de Marina Marcondes Machado (2010), sobre infância, performance e pedagogia do teatro, entre outros.

Importante salientar que cada pesquisadora tinha um tema específico de pesquisa: Amanda enfocou a diversidade de gênero (SUCUPIRA, 2016), Isadora enfocou a diversidade biográfica das crianças (RODRIGUES, 2016) e Luênia enfocou a diversidade de corpos, posturas e comportamentos (GUEDES, 2016).

\section{Pesquisa de campo/prática na escola}

Após as etapas de leitura e debate dos textos infantis e da revisão da bibliografia, fizemos contato com algumas escolas públicas do DF para a realização das pesquisas práticas com as crianças. As experiências foram realizadas em duas turmas de $6^{\circ}$ ano do CEFAB - Centro de Ensino Fundamental Athos Bulcão, localizado no Cruzeiro Novo/DF, e em duas turmas de $3^{\circ}$ ano da Escola Classe 15 de Sobradinho ${ }^{5}$, ambas localizadas em regiões administrativas do Distrito Federal.

Cada aluna preparou quatro planos de aula, com duração de uma hora e trinta minutos, totalizando seis horas, em quatro semanas. A organização das aulas foi baseada no que venho chamando de pesquisa etnográfico-propositiva (HARTMANN, 2017), combinada as propostas individuais de cada pesquisadora. Em todas elas, o foco de abordagem foi a promoção do protagonismo das crianças por meio de suas performances (cênicas, narrativas, fotográficas, etc.). A estrutura das aulas era basicamente a seguinte: realização de um jogo coletivo, contação de uma história da literatura infantil sugerida no survey (com ou sem

5 Agradecemos às professoras Wanuza Marques da Silva, do CEFAB, do Cruzeiro Novo, e Jeane Cristina dos Santos, da Escola Classe 15 de Sobradinho, que acolheram o projeto e foram fundamentais no desenvolvimento deste em suas respectivas escolas. 
o livro), por parte da pesquisadora, outro jogo ou atividade inspirada na história e abertura da roda para as crianças debaterem, questionarem e contarem suas histórias. ${ }^{6}$ Grande parte das aulas foram ministradas em um sistema de parceria formado por mim, as licenciandas e as crianças.

\section{Análise dos dados e redação dos relatórios finais}

\section{Crianças, performance e diversidade de gênero}

"Existem coisas que são de meninos e outras só de meninas. Mas e se trocasse as coisas, o que aconteceria?" (Ana-11 anos). Essa foi uma das perguntas registradas por Amanda, estudante da Licenciatura em Antropologia, durante sua pesquisa sobre diversidade de gênero. Ela constata, não sem um certo incômodo, que boa parte das pesquisas sobre gênero e infância não ouve o que as crianças têm a dizer a esse respeito. Explorando o binarismo de gênero que divide homens e mulheres de acordo com atividades, objetos e cores, mencionado por Buss-Simão (2013), Amanda observa que, embora as crianças dissessem, na roda de conversa, que essa divisão é "bobeira", um menino admitiu ter sofrido preconceito por ter ido de camisa rosa para a aula em sua antiga escola. A classificação de práticas cotidianas por gênero foi frequentemente citada nos cadernos de pesquisa das crianças. A frase "Se homem usa roupa rosa não significa nada.", por exemplo, foi escrita por Brenda, de 11 anos, junto do desenho de um menino vestido de rosa. (Brenda - 11 anos). Ao lado de uma foto do Kaká, famoso jogador de futebol, vestido com uma blusa rosa, lê-se a frase: "Não importa a cor, o gênero não muda", no caderno de Cibele, também de 11 anos. Já os desenhos de uma bicicleta, uma bola e um videogame, feitos por Giovani, de 11 anos, vêm seguidos das legendas: "Qual o problema de menina andar de bike?", "Qual o problema de menina jogar bola?", "Qual o problema de menina jogar videogame?" Podemos perceber aqui que, embora os marcadores de separação de gênero, como brinquedos, o vestuário, as cores, apareçam nos comentários das crianças, eles também são frequentemente questionados e problematizados.

Partindo das histórias "O casamento da onça com a filha da cotia", "O veado e a formiga", ambas de Ricardo Azevedo (2005), Maria Angula (tradição oral) e Maria e os três cavalinhos mágicos", de Heloisa Prieto (1998), Amanda procurou ouvir o que as crianças pensam e como agem em relação à diversidade

6 Deve-se notar que esse processo, de intercalar a narração de histórias como jogos corporais e de ritmo coletivos, visa ao estabelecimento de relações de confiança, escuta e "afinação" entre as crianças, preparando-as para suas performances individuais. 
de gênero. Como umA cotia pode se casar com umA onça? Quais os sentidos da palavra "veado"? Por que Maria Angula tinha de fazer a comida sempre? Como o filho do rei se apaixonou por Maria, mesmo pensando que ela fosse um rapaz? Dessas e de outras perguntas surgiram relatos, diante de todo o grupo, como o de Leonardo, que é frequentemente chamado de "veado", segundo ele porque tem a voz fina e porque gosta de dançar e andar com as meninas, ou de Patrícia, que contou que a chamavam Maria machona porque sua voz era mais grossa. Depois de ouvir a aterrorizante história de Maria Angula, Carolina compartilhou com o grupo que não entendia porque tinha de lavar a roupa de todos os irmãos, à mão, no tanque, enquanto estes ficavam brincando. "Lá em casa as mulheres é que ficam com o trabalho pesado", disse ela.

No último dia da oficina foi proposto um ensaio fotográfico com todas as crianças, individualmente. A ideia era que as crianças fossem fotografadas da maneira que quisessem. Muitas levaram roupas e maquiagem e outras experimentaram adereços e roupas que nós oferecemos. Além das poses de "modelo", com beijos para a câmera, e o pedido para fazerem fotos coletivas, nos chamou a atenção a participação de Gustavo, que era conhecido como o "valentão" da turma, frequentemente agressivo com os colegas: o menino vestiu um robe vermelho de seda e um chapéu e saiu desfilando pela sala. A prática desse exercício performativo permitiu a Gustavo experimentar outras formas de estar no mundo (e na sala de aula). Ele possivelmente vai continuar sendo o "valentão", mas no seu íntimo talvez entenda melhor o comportamento de Leonardo.

Durante o ensaio fotográfico, as crianças foram convidadas, depois de tirarem suas fotos, a escreverem num papelzinho um segredo, sem se identificarem. Em meio aos segredos surgiram muitas declarações de amor, mensagens de despedida, mas uma mensagem em especial nos chamou a atenção, pois dizia: "eu me odeio". O espaço de expressão havia sido aberto, tínhamos permitido a instabilidade. Nosso projeto estava acabando, mas ainda havia muito para ouvir, para entender, para trocar com as crianças.

$\mathrm{Na}$ conclusão de seu relatório, Amanda aponta que a prática de uma etnografia propositiva, na qual as crianças têm autonomia para intervir e redirecionar os rumos da pesquisa, não apenas rompe o silêncio dos livros e encontra mecanismos para apresentar e promover a diversidade - desafios apresentados por Tatiana Lionço e Débora Diniz (2009) na educação formal para a diversidade sexual e de gênero, como também fomenta os questionamentos das crianças sobre suas próprias práticas e saberes (SUCUPIRA, 2016). Como diz Arão Paranaguá de Santana: "As práticas docentes oriundas de processos colaborativos [...] são consideradas irmãs siamesas da performance, e abarcam uma noção de aprendizado e criação na qual os participantes interferem no fazer da coletividade, na qualidade de sujeitos (pro)ativos." (2015, p. 74). 


\section{Crianças, corpo e performance}

- Oi meu nome é Luênia, sou estudante de artes cênicas e vim aqui pra gente fazer algumas experiências cênicas, contar e ouvir histórias. Mas antes de começar quero saber se alguém tem alguma pergunta pra me fazer? Algum comentário? Eu não queria empurrar nada goela abaixo, todo desejo merece ser ouvido. Eles tinham perguntas:

- Você é brasileira? Você é desse planeta? Quem é sua mãe? Quanto tempo você vai ficar aqui?

Dessa forma, Luênia, estudante da Licenciatura em Artes Cênicas, descreve o início de sua pesquisa na escola, quando ela encontrou, numa manhã de terça-feira, "29 desejos", 29 crianças cheias de perguntas, desejosas de fala, de movimento, de troca. Inspirada na proposta de escrita performática de Elyse Pineau (2010), ela se utiliza da linguagem poética, epistolar para redigir seu artigo, e o endereça a uma de suas referências bibliográficas, a professora Marina Marcondes Machado, da UFMG, que também é uma das pesquisadoras vinculadas a este projeto?.

Luênia, que é professora de técnicas circenses e maquiadora profissional, aproveitou seus saberes e, com base em histórias como Onde a Onça Bebe Água, mencionada na epígrafe deste artigo, ou Catando Piolhos Contando Histórias, de Daniel Munduruku, desenvolveu um trabalho de "escuta sensível", explorando a diversidade corporal das crianças. Utilizando-se da metodologia comum do projeto: jogos coletivos e/ou atividades corporais, contação de histórias e abertura da roda para as histórias das crianças, Luênia explorou diversos recursos performativos, como a mudança na ambientação da sala (escurecendo-a para contar as histórias), exercícios nos quais as crianças, de olhos fechados, poderiam perceber o próprio corpo, a pintura corporal, a narrativa coletiva...

O lugar cercado causava alguma coisa que deixava a maioria dos desejos um tanto silenciados, mas não era um silencio só de voz, era um silencio de corpo inteiro. Eu queria reconhecer neles as formas de expressão dentro desse contexto. Lançar um olhar para a forma como os desejos (se) entendem, reconhecem e expressam e, a partir dessa reflexão, criar uma metodologia sensível, uma vivência artística comprometida com a experiência, seja ela expressa em gestos, corporeidades e/ou visualida-

7 Interessante "re-conhecer" os desdobramentos que as pesquisas com pedagogias performativas podem ter: a obra de Marina Machado foi referência para a estudante Luênia, que escreveu seu relatório em forma de carta para esta, que posteriormente publicou a carta da jovem licencianda em seu blog: http://agachamento.com/ 
des. Sem limitar a experiência no corpo. Pois cada corpo é um universo. (GUEDES, 2016, p. 6).

Em seu relatório, Luênia manifesta o esforço para dar voz ao corpo das crianças, abrir espaço para a expressão desses pequenos sujeitos-estudantes, incentivando sua postura autônoma e exploratória. Criando narrativas sobre sua história, as crianças podiam expressar e transformar artisticamente seu cotidiano.

\section{As crianças, autoras de suas histórias}

Isadora investigou a produção de narrativas pessoais das crianças, com base na narração de histórias, enfatizando o que chamou de "palavra-sentida", ou seja, a representação do ser ouvinte no ser-personagem que conta a história. De alguma forma, a história contada atinge também a história vivida pela criança.

Nessa experiência, foram selecionados dois livros em prosa e um de literatura dramática: Os fantásticos livros voadores de Modesto Máximo, de William Joyce (2012), Todos os sons tocam a alma, de Paulo Gonçalo (2010), Peças breves e deliciosas, de Paulo Hecker Filho (1997). Essa escolha proporcionou também a discussão sobre as diferenças entre os gêneros textuais, pois esta última obra trata-se de uma coletânea de pequenas obras dramatúrgicas. A estrutura das aulas se mantinha a mesma das demais, com sessão de contação, jogos, exercícios práticos e abertura da roda para as histórias das crianças.

Na primeira semana, após a narrativa da história, foi pedido que as crianças se dividissem em grupos e tentassem contar essa história por meio de imagens imóveis (estátuas), com seus próprios corpos. Na segunda semana, após a narrativa, o exercício foi criar coletivamente uma história usando cartões, com as indicações de personagem, local, sentimento, objeto, ação, sorteados aleatoriamente. Na terceira semana, foram realizadas experiências com um texto dramático. Posteriormente foram criados grupos que deveriam criar pequenas cenas dramáticas com base em suas experiências e trajetória de vida. Na quarta e última semana foram feitas "apresentações" das cenas, demandadas pelas próprias crianças, e avaliação do processo.

No processo promovido por Isadora, as narrativas trazidas pelas crianças evidenciaram fortemente as dificuldades vividas no ambiente escolar com a "indisciplina". Como sabemos, a escola prevê um modo por meio do qual a criança deve se comportar: sentada, em silêncio (BAITELLO JÚNIOR, 2012). 
A criança que por ventura distancia-se dessa perspetiva será classificada como "indisciplinada" e sobre ela incidirão dispositivos disciplinares, que visam conformá-la à normatividade vigente. Nas narrativas, cenas e nos debates com as crianças, no entanto, percebe-se claramente como a "indisciplina"pode ser forma de não submissão, um meio de resistência à homogeneização imposta pelo espaço escolar. (PROBST; JOE, 2014).

Com esta pesquisa propomos o enfrentamento das diferenças no contato com as histórias, corpos, sexualidades destes "outros", colegas de sala de aula, reconhecendo a instabilidades, incertezas e desconfortos na relação com a alteridade. Não pretendemos negar, suplantar ou subsumir as diferenças, mas encará-las, criticá-las, politizá-las, poetizá-las, performatizá-las. Pedagogias performativas podem permitir que, como Joaci e a Onça, vejamos as coisas pelas perspectivas dos "outros", refazendo-nos, quiçá, a nós mesmos.

\section{REFERÊNCIAS}

AZEVEDO, R. Contos de Bichos do Mato. São Paulo: Ática, 2005.

BAITELLO JÚNIOR, N. O Pensamento Sentado: sobre glúteos, cadeiras e imagens. São Leopoldo/RS: Editora Unisinos, 2012.

BRASIL. Ministério da Educação. Parâmetros Curriculares Nacionais: apresentação dos temas transversais, ética. Secretaria de Educação Fundamental. Brasília: MEC/SEF, 1997.

BUSS-SIMÃO, M. Gênero como possibilidade ou limite da ação social: um olhar sobre a perspectiva de crianças pequenas em um contexto de educação infantil. Revista Brasileira de Educação. Rio de Janeiro, v. 18, n. 55, 2013, p. 939-960.

CASTRO-GOMEZ, S. Ciências sociais, violência epistêmica e o problema da invenção do outro. In: LANDER, E. (Org.). A colonialidade do saber: eurocentrismo e ciências sociais. Perspectivas latinoamericanas. Colección Sur Sur, Ciudad Autônoma de Buenos Aires: CLACSO, 2005, p. 80-87.

GONÇALO, P. Todos os sons tocam a alma. São Paulo: Sowilo editora, 2010.

GUEDES, L. G. S. Histórias que o corpo conta: narrativas de pequenos contadores de histórias em escolas públicas no DF. Relatório de Iniciação Científica. Orientação de Luciana Hartmann. PROIC/UnB/CNPq, 2016.

HARTMANN, L. Interfaces entre a Pedagogia do Teatro e os Estudos da Performance. Educação, Santa Maria, v. 39, n. 3, p. 515-528, set./dez. 2014. 
HARTMANN, L. Equilibristas, viajantes, princesas e poetas: performances orais e escritas de crianças narradoras. Boitatá - Revista do GT de Literatura Oral e Popular da ANPOLL, Londrina, Universidade Estadual de Londrina, n. 20, p. 48-67, 2015.

HARTMANN, L. Desafios da diversidade em sala de aula: um estudo sobre performances narrativas de crianças imigrantes. Cadernos CEDES, Campinas, v. 37, n. 10, 2017, p. 45-64.

HECKER FILHO, P. Peças Breves e Deliciosas. Porto Alegre: Tchê!, 1997.

ICLE, G.; BONATTO, M. T. Por uma Pedagogia Performativa: a escola como entrelugar para professores-performers e estudantes-performers. Cadernos CEDES, Campinas, v. 37 , n. 101, 2017, p. 7-28.

JOYCE, W. Os fantásticos livros voadores de Modesto Máximo. São Paulo: Rocco, 2012.

LIONÇO, T.; DINIZ, D. Homofobia, silêncio e naturalização: por uma narrativa da diversidade sexual. In: LIONÇO, T.; DINIZ, D. (Org.). Homofobia \& Educação: um desafio ao silêncio. Brasília: Letras livres: EdUnb, 2009.

MUNDURUKU, D. Catando Piolhos, contando histórias. São Paulo: Brinque-Book, 2006.

OLIVEIRA, A. Antropologia e Antropólogos, educação e educadores: o lugar do ensino de Antropologia na formação docente. Revista Percursos. Florianópolis, v. 13, n. 01, 2012, p. 120-132.

PAIVA, A. Literatura fora da caixa: O PNBE na escola: distribuição, circulação e leitura. São Paulo: Ed. da UNESP, 2012.

PENA-RUIZ, H. Qu'est-ce que l'école? Paris: Gallimard, 2005.

PINEAU, E. L. Pedagogia crítico-performativa: encarnando a política da educação libertadora. In: PEREIRA, M. Performance e Educação: (des)territorializações pedagógicas. Santa Maria/RS: Ed. da UFSM, 2013, p. 37-58.

PINEAU, E. L. Nos cruzamentos entre a performance e a pedagogia: uma revisão prospectiva. Educação \& Realidade. Porto Alegre: n. 35, v. 2, 2010, p. 89-113.

PRIETO, H. Lá vem a história. São Paulo: Companhia das Letrinhas, 1998.

PROBST, M.; GARCIA, J. Sobre infância e (in)disciplina escolar: alguns apontamentos. Revista Contemporânea de Educação. Rio de Janeiro, v. 9, n. 18, 2014, p. 71-84.

RODRIGUES, I. L. As crianças, autoras de suas histórias. Relatório de Iniciação Científica. Orientação de Luciana Hartmann. PROIC/UnB/CNPq, 2016.

SANTANA, A. P. de. Performatividade e didática colaborativa na cena contemporânea da arte/eduçação. Caderno GIP-CIT. Salvador, ano 19, n. 35, 2015, p. 72-83.

SCHIEFFELIN, E. Problematizing Performance. In: HUGUES-FREELAND, F. (Ed.). Ritual, Performance, Media. London/New York: Routledge, 1997. p. 194-207. 
HARTMANN, L. Onça, veado, Maria: literatura infantil e performance em uma pesquisa...

SILVEIRA, R. M. H.; KAERCHER, G. Dois Papais, Duas Mamães: novas famílias na literatura infantil. Educação \& Realidade, Porto Alegre, v. 38, n. 4, 2013, p. 1191-1206.

STIGGER, V. Onde a Onça bebe água: a partir da obra de Eduardo Viveiros de Castro. São Paulo: Cosac Naify, 2015.

SUCUPIRA, A. P. Diversidade de Gênero e Literatura Infantil: a antropologia na escola. Relatório de Iniciação Científica. Orientação de Guilherme José da Silva e Sá. PROIC/ $\mathrm{UnB} / \mathrm{CNPq}, 2016$.

TURNER, V. Do ritual ao teatro: a seriedade humana do brincar. Trad. Michele Markowitz; Juliana Romeiro. Rio de Janeiro: Editora da UFRJ, 2015.

Texto recebido em 30 de outubro de 2017. Texto aprovado em 31 de outubro de 2017. 